\title{
Digital Na(t)ives? Variation in Internet Skills and Uses among Members of the "Net Generation"*
}

\author{
Eszter Hargittai, Northwestern University
}

\begin{abstract}
People who have grown up with digital media are often assumed to be universally savvy with information and communication technologies. Such assumptions are rarely grounded in empirical evidence, however. This article draws on unique data with information about a diverse group of young adults' Internet uses and skills to suggest that even when controlling for Internet access and experiences, people differ in their online abilities and activities. Additionally, findings suggest that Internet know-how is not randomly distributed among the population, rather, higher levels of parental education, being a male, and being white or Asian American are associated with higher levels of Web-use skill. These user characteristics are also related to the extent to which young adults engage in diverse types of online activities. Moreover, skill itself is positively associated with types of uses. Overall, these findings suggest that even when controlling for basic Internet access, among a group of young adults, socioeconomic status is an important predictor of how people are incorporating the Web into their everyday lives with those from more privileged backgrounds using it in more informed ways for a larger number of activities.
\end{abstract}

\section{Introduction}

Soon after the Internet started spreading across the mass population, concerns about its unequal distribution were voiced both in academic as well as policy circles (see, e.g., Compaine 2001; Hoffman and Novak 1998; National Telecommunications and Information Administration 1995). The initial focus of investigation and discussion was the so-called "digital divide" or the differences between the connected versus those not online at all. Undoubtedly, this was and remains an important area of inquiry given that a sizeable portion of the population even in the United States continues to be disconnected (Jones and Fox 2009; Zhang, Callegaro, and Thomas 2008) and since lack of Internet access excludes people from many important resources. Nonetheless, an underlying assumption permeates such a concentration of attention on the single question of connectivity: that once people go online issues of inequality are no longer a concern. In this article, following similar critiques by others (e.g., Barzilai-Nahon 2006; DiMaggio et al. 2004; Selwyn 2004), I challenge this 
assumption by offering an empirical investigation of differentiated Internet uses among a group of highly wired young adults.

Both in popular media (e.g., Boesveld 2008; O'Brien 2008) and elsewhere (Prensky 2001; Tapscott 1998), assumptions prevail about young people's inherent savvy with information and communication technologies (ICTs) simply because of the idea that they have had exposure to digital media throughout their lives. This perspective has led to a whole cohort of people being labeled "digital natives" (as opposed to "digital immigrants") (Prensky 2001) or the "Net generation" (Tapscott 1998) with the implication that differences in ICT uses is not a concern among the young given their widespread exposure and a supposed resulting comfort with and expert knowledge of digital media.

However, critics have warned that such assumptions about widespread digital skills among youth have not been backed up with empirical evidence (Bennett, Maton, and Kervin 2008). If anything, the more general scholarly literature on Internet use suggests that even once people cross the initial connectivity divide, numerous differences remain among them when it comes to how they incorporate the Internet into their lives (e.g., Barzilai-Nahon 2006; van Dijk 2005; DiMaggio et al. 2004). Consequently, it is important for research in this area to investigate differentiated uses among those online, so we have a better understanding of the contours of digital inequality and what processes underlie them even once the majority of Americans have crossed over to the connected side of the "digital divide." Focusing on young people (e.g., Palfrey and Gasser 2008), in particular, has the added benefit of also providing an empirical test of assumptions about the supposed inherent savvy of the so-called "digital natives."

In his address on December 6, 2008, then President-Elect Barack Obama talked about the relatively bad condition of broadband adoption in the United States (see comparisons with other countries in Organization for Economic Cooperation and Development 2008) and suggested that improving the state of affairs in this domain would be an important part of his public works construction program (Office of the President-Elect 2008). Indeed, the American Recovery and Reinvestment Act of 2009 allocated billions of dollars for such efforts (Committee on Appropriations 2009). While increasing broadband access is a necessary step toward making sure that Americans from diverse backgrounds have the potential to take advantage of all that the Internet has to offer, as sociologists of technology know (e.g., Bijker, Hughes, and Pinch 1987; and for communication technologies in particular: Starr 2004), the social implications of technologies are dependent on much more than inherent characteristics of technologies alone. Accordingly, achieving a knowledgeable Internet citizenry is unlikely to be resolved through a solely technical 
approach that focuses only on infrastructure without any consideration of the social processes and institutions in which people's Internet uses are embedded. To offer evidence of this proposition, this article analyzes data on the Internet uses of a diverse group of young adults who are all connected. By controlling for basic Internet access and use, it is possible to examine whether variation remains among users once basic connectivity has been achieved and whether divergent uses are randomly distributed or are systematically related to certain social factors.

In this article, I first briefly review the literature on Internet use and social inequality with particular emphasis on differentiated engagement with the medium by type of user background. I also consider work that has suggested the importance of looking at skill differences among users. I then present hypotheses derived from the literature about what may explain different levels of skill and differentiated types of uses. I then describe the unique data set I draw on to test the proposed hypotheses, followed by a presentation and discussion of results concluding with what the findings imply for our understanding of the relationship of Internet use and social inequality.

\section{Internet Use and Social Inequality}

Over a decade after the initial reports highlighting unequal diffusion of the Internet across the population were published (National Telecommunications and Information Administration 1995, 2000), the issue of differences in connectivity remains a concern as a sizeable portion of the population-a quarter of Americans - continues to be offline (Zhang, Callegaro, and Thomas 2008) and these differences persist along dimensions identified in the earliest reports such as the rural versus suburban and urban divides (Stern, Adams, and Elsasser Forthcoming). Additionally, work has started to identify very concrete repercussions - such as lower wages - of not being an Internet user (DiMaggio and Bonikowski 2008) suggesting that studying the contours of Internet use should be of interest to scholars of social stratification (Hargittai 2008). In particular, research has pointed out that it is not enough to look at differences among users and non-users, it is also essential to recognize that differentiated usage patterns among the connected have the potential to contribute to social inequality, too (e.g., van Dijk 2005; DiMaggio et al. 2004; Hargittai 2008; Selwyn 2004; Stern, Adams, and Elsasser Forthcoming; Warschauer 2002; Chen and Wellman 2005).

Most initial investigations of the digital divide tended to look at basic demographic and socioeconomic predictors of mere access such as age, gender, race/ethnicity, education, income, employment status, and place of residence (see, e.g., DiMaggio et al. 2004 for a review of much of this literature). Findings both from the reports of the National Telecommunications and Infor- 
mation Administration as well as scholarly investigations that followed found differences in basic connectivity by user background on all of these dimensions (e.g., Bimber 2000; Hoffman and Novak 1998; Loges and Jung 2001; National Telecommunications and Information Administration 1995, 1998). As time passed, some of these initial differences in access declined significantly, for example, in the domain of gender they all but disappeared (Ono and Zavodny 2003), leading some to conclude that "there is little reason for concern about sex inequalities in Internet access and usage now" (p. 111). However, others argued that inequalities may remain on other dimensions such as autonomy of use, experience, skill, social support, and types of uses (DiMaggio et al. 2004; Hargittai 2008). For example, reviewing the literature on gender and technology use more generally speaking, Hargittai and Shafer (2006) noted, among other things, that because of their larger share of household and child-rearing responsibilities, women have less leisure time for using the computer and browsing the Web suggesting that gender inequalities in Internet use remain even once we control for basic access differences.

Howard, Rainie, and Jones (2001) published one of the first papers to investigate types of activities by user background finding considerable differences by socioeconomic status. Analyzing data from a national sample of Internet users, these authors found that those with a college degree or more were more likely to seek health information, engage in financial transactions, research and look for job information, and get news than those with lower levels of education. In contrast, level of education was negatively correlated with online engagement in such activities as browsing just for fun, playing a game, or gambling online (Howard, Rainie, and Jones 2001). DiMaggio et al. (2004) referred to the distinction between the former and latter set of activity types presented by Howard et al. as "capital-enhancing" versus recreational suggesting that the former are types of online actions from which people may benefit whereas the latter likely have fewer pay-offs related to one's social status. Hargittai and Hinnant (2008) used this classification to examine how a national sample of American young adults aged 18-26 was incorporating the Internet into everyday life. The results from that paper were consistent with those found by Howard, Rainie, and Jones (2001): education was positively associated with capital-enhancing online activities. These findings suggest that Internet access may not, in and of itself, level the playing field when it comes to potential payoffs of being online. Rather, those from more privileged backgrounds may reap more of its benefits if they are more likely to use it in potentially beneficial ways (Hargittai 2008). Work examining differentiated Internet uses in other countries has found a similar relationship between socioeconomic status and usage (e.g., see Bonfadelli 2002 for Switzerland; Livingstone and Helsper 2007 for the UK; and Zillien and Hargittai 2009 for Germany). 
Trying to shed light on what it is about user context that leads to differentiated uses, some studies have also considered people's experiences and autonomy with the medium when examining the predictors of various online activities. Experience is usually understood in one of two ways: (1) the number of years someone has been online; and (2) the amount of time a person spends online. Autonomy stands for the freedom to use the technology when and where one wants to (Hargittai 2003). Hassani (2006) has looked at this question most directly and using nationally representative data about Americans' Internet uses found that those with more access points to the Internet are more likely to engage in capital-enhancing online activities such as health-information seeking and online banking compared with those who have fewer locations at which they can use the Web.

In addition to looking at how users' background characteristics and online experiences relate to Web activities, Hargittai and Hinnant (2008) also measured and thus were able to look at the relationship of skills and uses arguing that online abilities would likely influence how people use the medium (Kling 1998; Wilson 2000). Indeed, findings from that study suggest a strong positive relationship between these two variables whereby higher skills are associated with more capital-enhancing online activities. The addition of this variable helped uncover some of the black box of why uses differ among population groups.

\section{Hypotheses}

Findings from previous work suggest the following hypotheses regarding Internet users' online skills and diversity of Web usage.

\section{Hypotheses Regarding Skill}

H1a: Socioeconomic status will be positively related to Internet user skills.

H1b: Those with more autonomy in using the medium will exhibit higher levels of skill.

H1c: People with more experience using the Internet will have higher Web-use skills.

\section{Hypotheses Regarding More Diverse Uses of the Internet}

$\mathrm{H} 2 \mathrm{a}$ : Socioeconomic status will be positively related to diverse types of Internet uses.

$\mathrm{H} 2 \mathrm{~b}$ : Autonomy of use will be positively associated with diverse types of Internet uses.

$\mathrm{H} 2 \mathrm{c}$ : Internet use experience will show a positive relationship with diverse types of Internet uses.

$\mathrm{H} 2 \mathrm{~d}$ : Those with higher levels of Web user skill will use the Internet in more diverse ways than those with lower levels of skill. 


\section{Data and Methods}

Consistent in the literature is that both age (e.g., Jones and Fox 2009; Loges and Jung 2001) and education (e.g., Hargittai and Hinnant 2008; Howard, Rainie, and Jones 2001) are important predictors of varied Internet usage. By working with a population where these two factors are held constant, it is possible to investigate in more depth what other factors might matter in differentiated Web uses. Consequently, this article is based on a population where level of education is held constant and there is only small variation in age among participants, namely, all respondents are young adults and they all have equal levels of education.

The study's population is the entire first-year college class of an urban public research university that is not the flagship campus of the state's university system. ${ }^{1}$ In winter, 2007, a paper-pencil survey was administered in class to students in the one course on campus that is required for everybody thereby avoiding any selection bias as to who is enrolled in the class. There were 87 sections in this course, out of which 85 took part in the project for a 98 percent section-participation rate. Students who were absent on the day of the survey administered in their respective sections were excluded yielding an overall 82 percent response rate from among those enrolled in the course. The survey was administered on paper rather than online so as not to bias against those who spend less time using the Internet or who may feel less comfortable filling out forms online. Since both time spent online and level of Web user skill are variables of interest in the study, it was important not to use a data collection method that might be related to these variables.

While a nationally representative sample would be the most ideal for testing the above-proposed hypotheses, no such data set exists to date with sufficiently nuanced information about the variables of interest here. Worthy of note is the fact that some other results published from this data set (Hargittai 2007) have been replicated in subsequent research on a national scale (Nielsen Wire 2009) suggesting that certain findings may be generalizable well beyond the population covered in the study. Nonetheless, it is important to stay conscious of the fact that the sample is not representative especially on age and education. Since existing literature has identified both of these variables with higher levels of Internet use, if anything, this suggests that findings from this group about the potential role of factors such as socioeconomic status are likely to be conservative compared with a more diverse sample that were to include people of all ages and those with lower educational backgrounds. 


\section{Measures: Independent Variables}

Students were asked their year of birth to calculate age. Parental education is used as a proxy for socioeconomic status (Sewell 1971). ${ }^{2}$ Respondents are asked to report the level of education of both their mother and their father using the following categories: (1) less than high school degree; (2) high school degree; (3) some college; (4) college degree (for example: B.A., B.S., B.S.E); and (5) advanced graduate (e.g., master's, professional, Ph.D., M.D., Ed.D.). Using information from these two questions, I created a parental education variable that is assigned the value of the highest education by either parent, for example, if a student has a mother with a high school degree and a father with a college degree, the parental education variable for that student is coded as "college degree." To measure race and ethnicity, students were first asked if they were Hispanic or of Latino origin. Then they were asked their race including the following categories: (1) white/Anglo/Caucasian/Middle Eastern; (2) black/African American; (3) Asian; (4) American Indian or Alaskan Native; and (5) other. Most responses in the "Other" category indicated Hispanic origin and were recoded accordingly. The final categories are: Hispanic, non-Hispanic African American, non-Hispanic Asian American, non-Hispanic Native American, and non-Hispanic white.

To be able to identify the importance of technological context of use, participants were asked some questions about the availability of computer and Internet-related resources in their everyday lives. Respondents were asked whether they own a laptop, measured as a dichotomous variable. The survey asked about different locations where participants have access to the Internet (as opposed to actually using it regularly at various locations) by having the choice to check off all applicable locations from a list of 11 options. I created a summary variable from these; the final measure ranges from 0 to 11 locations. Two measures are used to assess experience with the Internet: number of use years and hours spent on the Web weekly. The former measure is calculated using information from survey questions that ask about the stage in one's academic career when the student first became an Internet user (i.e., during elementary school, middle school, or a particular year in high school). User years is capped at 10 (a response given by just under 20 percent of the sample) and is logged in the analyses because of the idea that there are diminishing returns to additional years as the number of years increases. Time spent on the Web weekly (excluding email, chat and voice services) is derived from answers to two questions asking about hours spent on the Web on an average day; one inquiring about weekdays, the other about an average Saturday or Sunday. This measure ranges from 0 to 42 hours and is also logged in the analyses for reasons similar to logging number of use years. 


\section{Measures: Dependent Variables}

To measure Web user skill, the data set includes a previously developed and validated instrument (Hargittai 2005, 2009) similar to items included in the Internet Society Module of the General Social Survey 2000 (National Opinion Research Center 2000; Wasserman and Richmond-Abbott 2005). Respondents were asked to rate their level of understanding of 27 Internetrelated terms on a five-point scale. These 27 scores were then added up to create the skill index (Cronbach's alpha $=.94$ ). The possible range for the index is $0-108$, observed values range from 2 to 108 with a mean of 54.32 (SD: 22.64).

I measure diversity of Web usage by creating an index of types of online activities in which respondents reported engaging. The survey asked about use of the Internet for various purposes (e.g., getting news, financial information, health information, checking weather forecasts, downloading music, looking up recipes, etc.) as well as four school-related activities in particular (i.e., looking up the definition of a word, checking facts, getting information for school work, and visiting a library's Web site). Respondents indicated frequency of use for 25 different information-seeking purposes ranging from never to several times a day with six additional categories in between. These variables were recoded to binary values to indicate whether students engaged in certain online activities on a weekly basis or not. ${ }^{3}$ The summary of the 25 binary variables then yields the Web-use diversity score $($ Cronbach's alpha $=.78) .{ }^{4}$ While it may be the case that individual activities have different predictors, of main interest in this article is the diversity of usage based on the argument that regularly engaging in more types of activities online is going to be generally more beneficial than doing fewer things online.

\section{Methods of Analysis}

First, I present bivariate analyses of the data to illustrate the relationship between the variables of most interest, namely, the relationship of parental education, gender, and race/ethnicity to the technical context of people's online experiences as well as skills and use diversity. Then, I use ordinary least squares (OLS) regression to look at predictors of skill level and diversity of Web usage while controlling for various social and use context factors. Since both outcome variables (skill score and number of types of Web sites visited weekly) are interval level and meet the requirement of normal distribution, this method is most appropriate. The correlations among the independent variables are not so high as to cause a concern of multicollinearity. 


\section{The Sample}

The sample includes 1,060 first-year students the majority of whom are 18 or 19 years old (97 percent are this age). ${ }^{5}$ Just over half are women at 55.8 percent. Over a quarter (26.4 percent) of students come from families where neither parent has more than a high school education and overall almost half come from families where neither the father nor the mother has a college degree (46.5 percent). Just over a third (34.4 percent) come from families where at least one parent has a college degree, but no higher education, and just under a fifth (19.1 percent) of participants have at least one parent with a graduate degree. Less than half of the sample is white, non-Hispanic at 42.7 percent, Asian and Asian American non-Hispanic students account for 29.6 percent of respondents, just under a quarter are Hispanic (18.8 percent), 7.7 percent are African American non-Hispanic, and a few Native Americans took part in the study. ${ }^{6}$ Table 1 presents these figures in detail.

\section{Table 1}

Background of Study Participants

Percent

Women

55.8

Age

18 years

64.8

19 years

20-29 years

Parents' highest level of education

Less than high school

High school

19.0

Some college

College

Graduate degree

Race and ethnicity

African American, non-Hispanic

Asian American, non-Hispanic

Hispanic

Native American, non-Hispanic

White, non-Hispanic 


\section{The Relationship of User Background, Technological Context of Use, and Experiences}

I consider the relationship of user characteristics and several measures of technology use in an attempt to identify where exactly the contours of inequality lie in the domain of Internet usage. Figures 1 and 2, and Table 2 look at
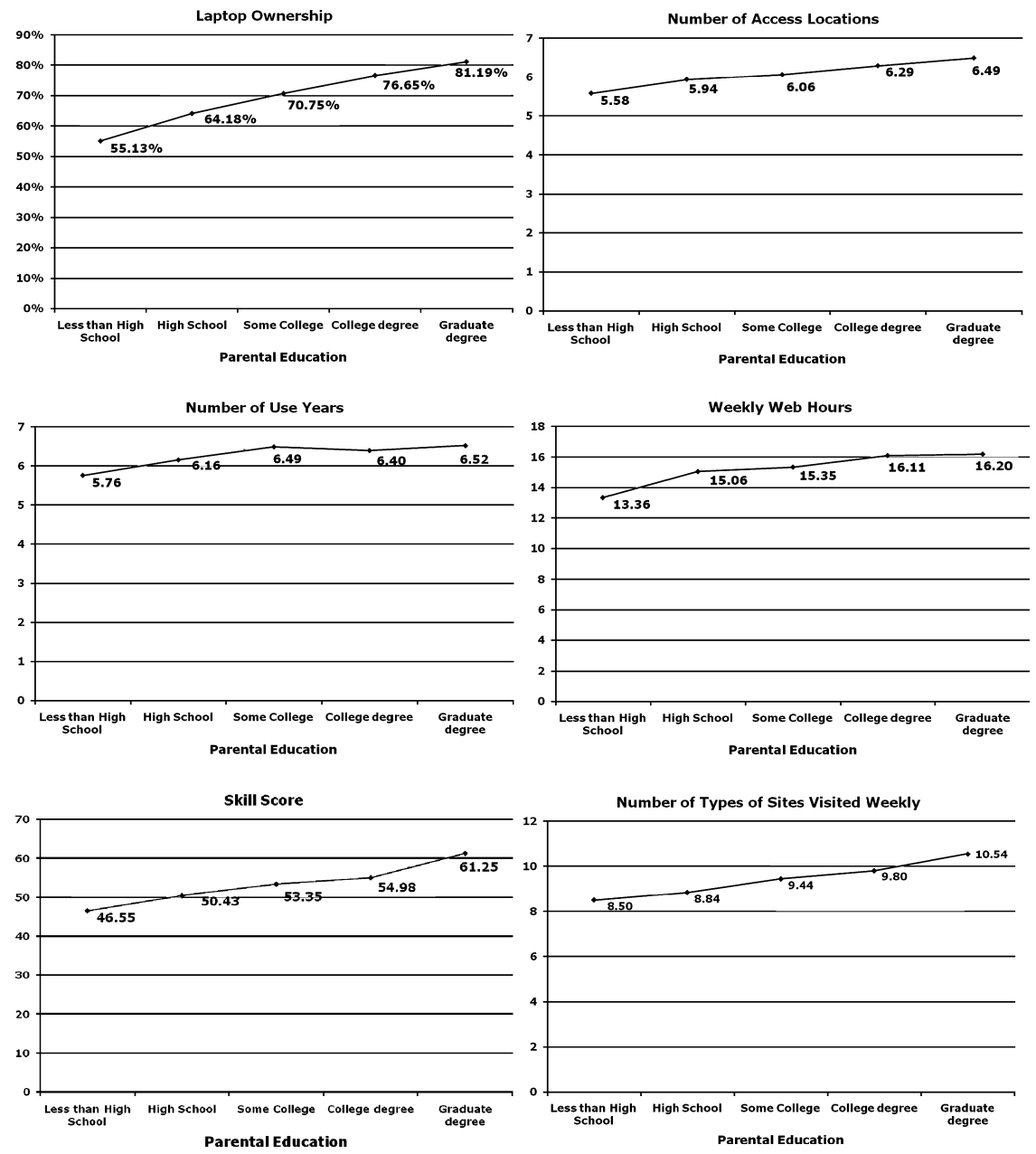

Figure 1

Relationship of Parental Education to Computer and Internet Use Variables. 

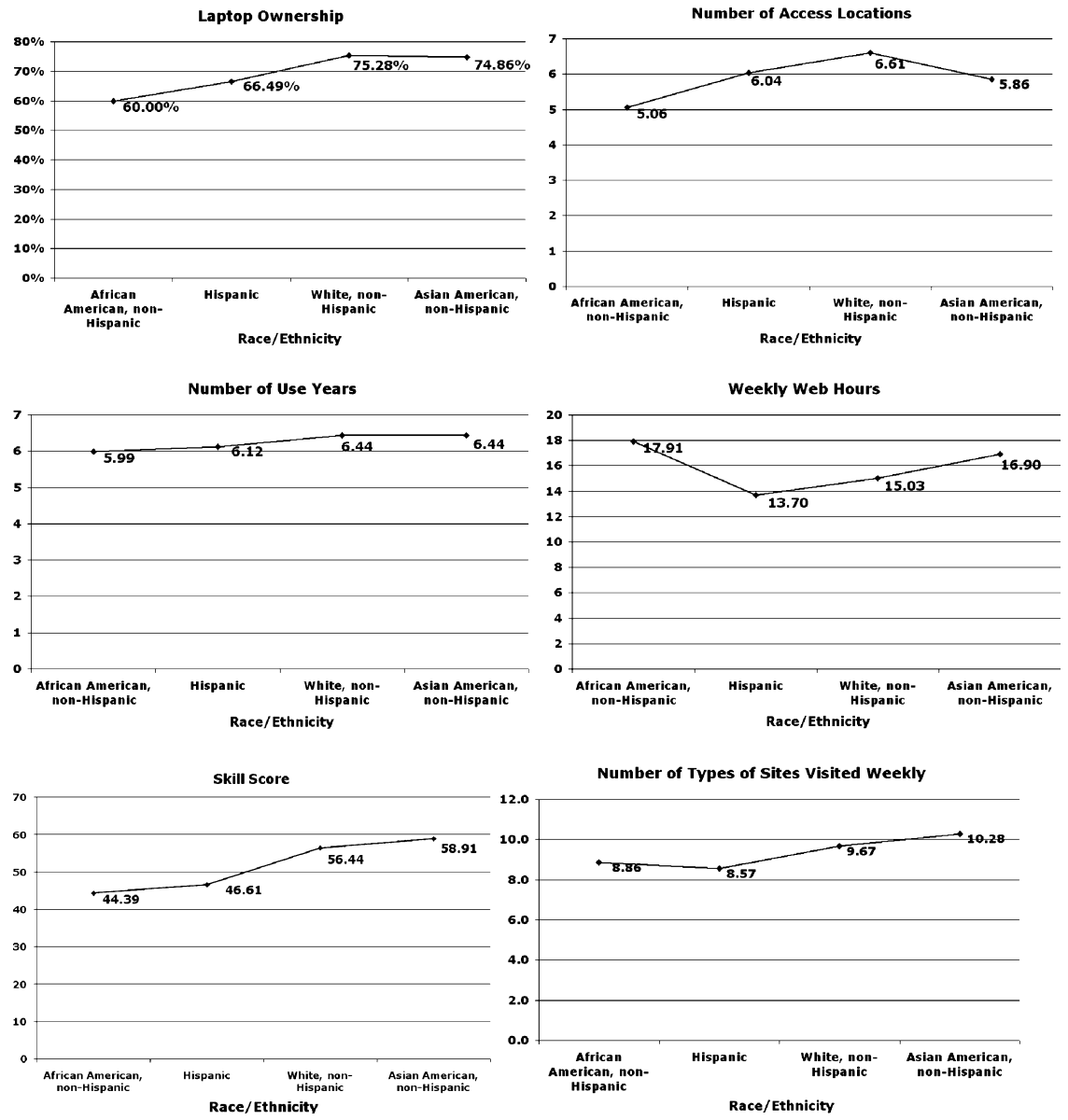

\section{Figure 2}

Relationship of Race/Ethnicity to Computer and Internet Use Variables.

the binary relationship of parental education, race/ethnicity, and gender to measures of technical context of Internet uses, skill, and Web-use diversity, respectively. In Figure 1, parental education is broken into five categories depicted on the $x$-axis ranging from students coming from families where both parents have less than a high school degree to students who have at least one parent with a graduate degree. The six graphs each look at one aspect of use: laptop ownership, number of access locations, number of use years, weekly Web hours, skill score, and number of types of sites visited. In all of these 
Table 2

Descriptive Statistics of Internet Use Variables Used in the Analyses

Project participants

\begin{tabular}{lrrr}
\cline { 2 - 3 } & Mean & SD & \multicolumn{1}{c}{$N$} \\
\hline Owns laptop (0 = no, 1 = yes) & .72 & .45 & 1,060 \\
Number of access locations (0-11) & 6.16 & 2.11 & 1,060 \\
Number of use years (0-10) & 6.35 & 2.02 & 1,051 \\
Weekly Web hours (0-42) $_{\text {Summary skill item score }(0-108)^{\mathrm{a}}}$ & 15.54 & 10.04 & 1,056 \\
${\text { Diversity of sites visited }(0-25)^{\mathrm{a}}}$ & 54.32 & 22.64 & 1,060 \\
& 9.58 & 3.98 & 1,060
\end{tabular}

Note: ${ }^{\text {a}}$ Possible range in parentheses.

cases, there is an upward trajectory as we move from students with parents having lower levels of education to students from more educated parental backgrounds. For example, while just over half (55.1 percent) of students from the lowest parental education category—less than high school education-own laptops, four out of five (81.2 percent) among the highest parental education group have such a resource at their disposal. The graph showing number of use years is the only one where there is no clear relationship between the two variables as the values level off among those students whose parents have at least some college education. Even there, however, those in the two lowest parental education categories have fewer experiences with the Internet.

As the graphs in Figure 2 suggest, the relationship of race/ethnicity to various Internet use measures is mixed. For the most part, African American and Hispanic students score lower on the resource and experience measures than whites and Asian Americans. Students in the latter two categories tend to be similar regarding resources and experiences. This relationship does not hold, however, in the case of autonomy (as measured by number of access locations) and weekly hours spent online. Regarding the former measure, whites have the most autonomy followed by Hispanic students and then Asian Americans. Concerning time spent online, African Americans claim to be surfing the Web more than their peers in any other category.

As regards gender (Table 3), we find statistically significant differences among the young men and women in this sample when it comes to their Web-use autonomy and experiences on all, but one of the measures. Men are 
Table 3

Relationship of Gender and Computer and Internet Use Variables ${ }^{\mathrm{a}}$

\begin{tabular}{lllllll}
\hline & $\begin{array}{l}\text { Laptop } \\
\text { ownership } \\
(\%)\end{array}$ & $\begin{array}{l}\text { Number of } \\
\text { access } \\
\text { locations }\end{array}$ & $\begin{array}{l}\text { Number } \\
\text { of use } \\
\text { years }\end{array}$ & $\begin{array}{l}\text { Weekly } \\
\text { Web } \\
\text { hours }\end{array}$ & $\begin{array}{l}\text { Skill } \\
\text { score }\end{array}$ & $\begin{array}{l}\text { Number of } \\
\text { types of } \\
\text { sites visited }\end{array}$ \\
\hline Men & 73.99 & 6.41 & 6.56 & 16.58 & 65.15 & 10.73 \\
Women & 71.07 & 5.95 & 6.19 & 14.72 & 45.73 & 8.68 \\
\hline
\end{tabular}

Note: ${ }^{a}$ All differences are statistically significant except for Laptop Ownership.

slightly more likely to own a laptop than women although this difference is not statistically significant. Men report, on average, about half an access location more than women. Male respondents have been online for longer than female participants and also spend more hours on the Web weekly. The difference in their reported skill scores is the starkest and we also observe variation in their diversity of online activities.

\section{Explaining Differences in Skill}

I consider the relationship of user characteristics and several measures of technology use in an attempt to identify the contours of inequality in this domain. Bivariate statistics help us understand basic trends, but it is important to look at the relationship of various user characteristics while controlling for other factors to get a better sense of what factors-demographic, socioeconomic, and contextual-are mainly responsible for variations in skill. Accordingly, I use multiple regression analyses to examine predictors of skill level. Table 4 presents the findings from two OLS regression models with skill as the outcome variable. First, I simply look at how age, gender, parental education, and race/ethnicity relate to skill. Then, I supplement the model with information about autonomy (laptop ownership, number of access locations) and experience (years of use, weekly Web hours).

Results show that women claim lower levels of know-how regarding Internet-related terms. Regarding parental educational background, findings suggest that even when we hold respondents' education level constant-all respondents in the sample are in their first year of college-parental education nonetheless matters in explaining variation in user skill. Those from families with at least one parent holding a graduate degree (the baseline category) exhibit statistically significantly higher level know-how about the Web than 
Table 4

OLS Regression Predicting Skill

\begin{tabular}{lcc} 
Variable & $B$ & $B$ \\
\hline Age & $.57(.79)$ & $.80(.74)$ \\
Female (=1) & $-17.94 * * *(1.30)$ & $-15.98 * * * *(1.22)$ \\
Parental education & & \\
$\quad$ Less than high school & $-7.84 * * *(2.92)$ & $-4.45(2.76)$ \\
$\quad$ High school & $-5.31 * *(2.09)$ & $-3.78^{*}(1.98)$ \\
$\quad$ Some college & $-3.37(2.07)$ & $-2.44(1.94)$ \\
$\quad$ College & $-4.33 * *(1.81)$ & $-3.79 * *(1.70)$ \\
Race/ethnicity & & \\
$\quad$ African American, non-Hispanic & $-6.12 * *(2.51)$ & $-5.14 * *(2.39)$ \\
$\quad$ Asian American, non-Hispanic & $2.01(1.51)$ & $1.92(1.44)$ \\
$\quad$ Hispanic & $-6.26 * * *(1.87)$ & $-5.61 * * * *(1.75)$ \\
Owns laptop & & $-.542(1.37)$ \\
Number of access locations & & $1.59 * * * *(.30)$ \\
Number of use years (logged) & & $10.16 * * *(2.13)$ \\
Weekly Web hours (logged) & $5.21 * * * *(.91)$ \\
Intercept & $58.70(14.75)$ & $1.45(14.87)$ \\
$N$ & 1,032 & 1,020 \\
$R$-square & .217 & .325 \\
Adjusted $R$-square & .210 & .316 \\
\hline
\end{tabular}

Note: Standard errors are in parentheses. For parental education, graduate degree is the omitted category, for race it is white, non-Hispanic.

$*<.1, * * p<.05, * * * p<.01, * * * * p<.001$.

others even when we control for other background characteristics. Regarding race and ethnicity, compared with whites (the omitted category), African Americans and Hispanic students report knowing less about the Internet. These findings hold even when we control for Internet resources and experiences as per the second model. That is, while number of access locations, number of use years, and weekly Web-use hours are all positively related to online skills, they do not account fully for the relationship of gender, education, and race/ethnicity to skills. Rather, there is an independent relationship among these variables suggesting that user background relates to online know-how beyond the technical context of use. 
Since it is cost-prohibitive to gather data on the actual skills of such a large group of respondents, we must rely on self-assessed online abilities when measuring Web-use skills. Prior research that was able to measure both actual and perceived online abilities found (Hargittai and Shafer 2006) that women rate their online know-how lower even when we control for actual observed skills. However, work has also found (Hargittai and Walejko 2008) that even self-perceived online abilities-using the same measures as applied here-exhibit a relationship with outcomes such as online content sharing so whether real or imagined, different levels of skill can have real consequences. That is precisely what the next set of analyses explores here. Having established that Web-use skill is not randomly distributed among a group of young adults who have grown up with digital media, of interest next is whether these differences in Internet skills translate into divergent online activities. The following section discusses the results of analyses that address this question.

\section{Explaining Diversity in Internet Uses}

Table 5 presents the results of three OLS regression models looking at diversity of Internet usage. ${ }^{7}$ The first model considers how user background relates to the number of types of information-seeking activities in which people engage online regularly. Although most respondents in the sample are nearly the same age (65 percent are 18, 32 percent are 19), age still shows a significant relationship with diversity of usage; older students report visiting more types of site on a weekly basis. Women report visiting fewer types of sites than men. Students whose parents have no more than a high school degree visit a lower diversity of sites than those whose parents have a graduate degree. Regarding race and ethnicity, Asian Americans visit more types of sites while students of Hispanic origin visit fewer types of sites than white, non-Hispanics in the group.

To what extent are these findings driven by the different levels of technological context of use identified earlier? To account for variation in technical resources, the second model presented in Table 5 considers the above variables while holding measures of Internet autonomy and experience constant. Age and gender remain significant, but the statistical significance and size of coefficients for parental education have decreased. We also no longer observe a statistically significant relationship between Hispanic origin and diverse types of Web uses. Rather, we find that having a laptop and especially having a larger number of access points to the Internet are important predictors of engaging in more diverse types of information-seeking activities online. Moreover, number of years a student has been an Internet user and how much time he or she spends online matters 


\section{Table 5}

OLS Regression Predicting Diverse Types of Web Uses

\begin{tabular}{|c|c|c|c|}
\hline Variable & $B$ & $B$ & $B$ \\
\hline Age & $.36 * *(.15)$ & $.34 * *(.14)$ & $.30 * *(.13)$ \\
\hline Female $(=1)$ & $-1.80 * * * *(.24)$ & $-1.42 * * * *(.23)$ & $-.59 * *(.24)$ \\
\hline \multicolumn{4}{|l|}{ Parental education } \\
\hline $\begin{array}{l}\text { Less than high } \\
\text { school }\end{array}$ & $-1.24 * *(.55)$ & $-.51(.51)$ & $-.28(.49)$ \\
\hline High school & $-.98 * *(.39)$ & $0.65 *(.37)$ & $-.45(.35)$ \\
\hline Some college & $-.46(.39)$ & $-.18(.36)$ & $-.06(.35)$ \\
\hline College & $-.46(.34)$ & $-.34(.32)$ & $-.14(.31)$ \\
\hline \multicolumn{4}{|l|}{ Race/ethnicity } \\
\hline $\begin{array}{c}\text { African American, } \\
\text { non-Hispanic }\end{array}$ & $-.12(.47)$ & $.24(.44)$ & $.50(.43)$ \\
\hline $\begin{array}{l}\text { Asian American, } \\
\text { non-Hispanic }\end{array}$ & $.55 *(.28)$ & $.66 * *(.27)$ & $.56 * *(.26)$ \\
\hline Hispanic & $-.58 *(.35)$ & $-.34(.32)$ & $-.05(.31)$ \\
\hline Owns laptop & & $.47 *(.25)$ & $.50 * *(.24)$ \\
\hline $\begin{array}{l}\text { Number of access } \\
\text { locations }\end{array}$ & & $.43 * * * *(.06)$ & $.35 * * * *(.06)$ \\
\hline $\begin{array}{l}\text { Number of use } \\
\text { years (logged) }\end{array}$ & & $.75^{*}(.40)$ & $.22(.39)$ \\
\hline $\begin{array}{l}\text { Weekly Web } \\
\text { hours (logged) }\end{array}$ & & $1.56 * * * *(.17)$ & $1.14 * * * *(.17)$ \\
\hline Skill score & & & $.05 * * * *(.01)$ \\
\hline Intercept & $4.51(2.78)$ & $-4.25(2.77)$ & $-4.33(2.66)$ \\
\hline$N$ & 1,032 & 1,020 & 1,020 \\
\hline$R$-square & .09 & .23 & .29 \\
\hline Adjusted $R$-square & .08 & .22 & .28 \\
\hline
\end{tabular}

Note: Standard errors are in parentheses. For parental education, graduate degree is the omitted category, for race it is white, non-Hispanic.

$*<.1, * * p<.05, * * * p<.01, * * * * p<.001$.

considerably. These findings suggest that beyond basic access, quality of use context matters for how people incorporate the Internet into their everyday lives. 
What else may account for the observed variation in diversity of usage types? The final model in Table 5 adds the Internet skill score to the model. This variable is positively and significantly related to usage diversity $(p<.0001)$ and its inclusion improves the model fit. It also diminishes the significance of some other variables: although the gender coefficient is still significant, it is considerably lower in size; parental education is no longer related to diversity of Web usage and number of use years no longer matters much either. Overall, these findings suggest that familiarity with the medium is very much related to how people use the Internet and user savvy mediates some of the otherwise observed relationships of user background and online activities.

\section{Conclusion}

Certain differences in Americans' Internet uses have been widely documented over the years, including the importance of age and education in whether people are online. These investigations may lead one to believe that once we control for such factors, differences in usage will no longer remain. By looking at a universally wired group of first-year college students and thereby largely controlling for two of the most important variables-age and education-found to be important in the literature on differentiated Internet uses, this study is able to examine whether factors beyond these user characteristics contribute to digital inequality.

A particularly unique element of this article is that it is able to consider differences in users' Web-use skills. While popular rhetoric would have us believe that young users are generally savvy with digital media, data presented in this article clearly show that considerable variation exists even among fully wired college students when it comes to understanding various aspects of Internet use. Moreover, these differences are not randomly distributed. Students of lower socioeconomic status, women, students of Hispanic origin, and African Americans exhibit lower levels of Web know-how than others. Undoubtedly, differentiated contexts of uses and experiences may explain these variations so it is important to examine those associations as well. Indeed, as the analyses presented in this article suggest, autonomy of use and Web user experience are both positively related to skill. However, even when controlling for these factors, skill differences remain by type of user background.

Regarding diverse types of Internet uses, results suggest that those from a lower socioeconomic background, women, and students of Hispanic origin tend to engage in fewer information-seeking activities online on a regular basis than others. When controlling for user context, however, many of these associations no longer hold. Rather, autonomy of use (both laptop ownership and number of access locations) and amount of time spent online (although 
not number of years a student has been a user) matter in predicting diversity of Web usage. Parental education and ethnicity no longer explain differentiated uses although women report doing fewer things online even when we control for user context. Additionally, Asian American students engage in more activities on the Web regardless of resources and experience.

As for the unique variable whose significance most studies are unable to consider, Internet user skill turns out to be strongly associated with diverse types of uses. Students with higher level know-how engage in more activities online than those who understand the Web less. Of course, these two factors likely have a reinforcing relationship. More diverse types of uses probably feed back into increased user savvy. Nonetheless, recognizing this relationship is important in understanding what factors explain differentiated uses among people, especially among young people who are commonly perceived and assumed to be universally knowledgeable about and generally comfortable with all facets of the Web. Regarding widespread assumptions about the inherent digital savvy of young users often referred to as "digital natives," it is important to note that the data presented here do not support the premise that young adults are universally knowledgeable about the Web. Rather, we observe systematic variation in online know-how even among a highly wired group of young adults based on user background.

Overall, the results of this study show support for the importance of taking a more nuanced approach to studying the relationship of Internet use to social inequality. Far from being simply dependent on mere access, systematic differences are present in how people incorporate digital media into their lives even when we control for basic connectivity. Moreover, these differences hold even among a group of college students, precisely the type of population that popular rhetoric assumes to be universally wired and digitally savvy. These assumptions are not supported by the evidence, however. The particular societal positions that people inhabit are reflected in their Internet uses. Those who are already more privileged tend to have more Internet use autonomy and resources, more online experiences, higher levels of know-how and report engaging in more diverse types of uses than the less privileged, precisely the group that would stand a better chance of benefitting from these activities if they were more engaged with them. Given that the population under consideration here already represents a relatively privileged group (all respondents are in college), findings concerning the relationship of socioeconomic status to Internet know-how and diversity of usage are likely to be conservative as compared with what we might find for a more nationally representative sample. In sum, while the Internet certainly has the potential to level the playing field by offering numerous opportunities to its diverse users, the results 
presented in this article suggest that as things stand, the more privileged stand to benefit from it more than those in less advantageous positions raising concerns about possibly increased rather than decreased inequality resulting from the spread of Internet use across the population.

\section{ENDNOTES}

*The author thanks Mike Stern and the anonymous reviewers for their helpful comments. She appreciates the support of faculty and staff at the University of Illinois-Chicago for making this study possible, namely, Mary Case, Ann Feldman, Tom Moss, and Karen Mossberger. Additionally, she thanks the following people for their assistance with data collection and entry: Waleeta Canon, Gina Walejko, Soo An, Dan Li, and the group of undergraduate research assistants in the Web Use Project group during the 2006-2007 academic year. She is very grateful for the generous support of the John D. and Catherine T. MacArthur Foundation through its Digital Media and Learning initiative. She is also indebted to the Berkman Center for Internet \& Society at Harvard University, the Center for Advanced Study in the Behavioral Sciences at Stanford University, and The Lenore Annenberg and Wallis Annenberg Fellowship in Communication. She thanks the support offered by Northwestern University's Research Grants Committee, the School of Communication Innovation Fund, and the Department of Communication Studies Research Fund. Please direct correspondence to Eszter Hargittai, Communication Studies Department, Northwestern University, 2240 Campus Dr., Evanston, IL 60208, USA; e-mail: eszter@northwestern.edu

${ }^{1}$ The author of this piece is not now nor has ever been affiliated with this school. Selection of the campus was because of the diverse composition of the student body and the importance of that factor to the questions of interest in the study.

${ }^{2}$ Although measures of income would be ideal for a study examining the relationship of Internet use and socioeconomic status, reliable information of this sort is nearly impossible to collect from a college population for several reasons. For one, students rarely know the income of their parents. Also, students' own incomes are not indicative of their financial resources since many are still dependent on parental support. Additionally, asking students about household income is problematic since many live with roommates about whose financial situation they may know little.

${ }^{3}$ I also used an alternate way of calculating the site diversity index. Instead of taking weekly visits as the cut-off point, I created the binary measures based on whether a respondent fell in the half of the sample that had engaged in a certain activity the most. Although this method results in a different overall diversity index score, the results are robust when it comes to predicting the score as per the final analyses presented in the article (see Table 5).

${ }^{4} \mathrm{Absent}$ in this measure is the use of the Internet for interpersonal communication. Because information seeking and interpersonal communication are considerably different activities, I did not want to collapse them and opted for the investigation of the one for which I have a wide range of measures and whose summary yields considerable variance.

${ }^{5}$ The instrument included a question verifying students' attentiveness to the survey. A small portion of students (3.4 percent) responded incorrectly to this question, suggesting that they were checking off responses randomly instead of replying to the substance of the questions. These students have been excluded from the data and analyses presented here so as to minimize error introduced through such respondents. The 1,060 students included here all responded to the attention verification question correctly. 


\begin{abstract}
${ }^{6}$ Because of their small numbers ( $n=12$ or less than 1.2 percent of the sample), Native American students are excluded from the analyses.

${ }^{7}$ It is worth reminding the reader that the analyses presented in this section look at overall diversity of usage rather than focusing on the predictors of any one particular online activity on its own. It may well be that different types of uses have varying predictors and the results presented here should not be read as generalizable to each individual activity. Rather, the point is to consider what explains usage diversity on the aggregate based on the premise that there is value associated with using the Internet regularly for a larger number of activities.
\end{abstract}

\title{
REFERENCES
}

Barzilai-Nahon, Karine. 2006. "Gaps and Bits: Conceptualizing Measurements for Digital Divide/s." The Information Society 22:269-78.

Bennett, Sue, Karl Maton, and Lisa Kervin. 2008. "The "Digital Natives" Debate: A Critical Review of Evidence." British Journal of Educational Technology 39:775-86.

Bijker, W., T. Hughes, and T. Pinch, eds. 1987. The Social Construction of Technological Systems: New Directions in the Sociology and History of Technology. Cambridge, MA: MIT Press.

Bimber, Bruce. 2000. "Measuring the Gender Gap on the Internet." Social Science Quarterly $81: 868-76$.

Boesveld, Sarah. 2008. "Gadget-Savvy but Socially Inept? Tech may be Altering Your Mind." in Globe and Mail.

Bonfadelli, Heinz. 2002. "The Internet and Knowledge Gaps. A Theoretical and Empirical Investigation." European Journal of Communication 17:65-84.

Chen, Wenhong and Barry Wellman. 2005. "Minding the Gaps: the Digital Divide and Social Inequality." Pp. 523-45 in Blackwell Companion to Social Inequalities, edited by M. Romero and E. Margolis. Oxford: Blackwell.

Committee on Appropriations. 2009. The American Recovery and Reinvestment Act of 2009. Washington, DC: United States House of Representatives.

Compaine, Benjamin M., ed. 2001. The Digital Divide: Facing a Crisis or Creating a Myth? Cambridge, MA: The MIT Press.

van Dijk, Jan. 2005. The Deepening Divide: Inequality in the Information Society. Thousand Oaks, CA: Sage Publications.

DiMaggio, Paul and Bart Bonikowski. 2008. "Make Money Surfing the Web? The Impact of Internet Use on the Earnings of U.S. Workers." American Sociological Review 73:227-50.

DiMaggio, Paul, Eszter Hargittai, Coral Celeste, and Steven Shafer. 2004. "Digital Inequality: From Unequal Access to Differentiated Use." Pp. 355-400 in Social Inequality, edited by Kathryn Neckerman. New York: Russell Sage Foundation.

Hargittai, Eszter. 2003. How Wide a Web? Inequalities in Accessing Information Online. Princeton, NJ: Sociology Department, Princeton University.

- 2005. "Survey Measures of Web-oriented Digital Literacy." Social Science Computer Review 23(3):371-79.

2007. "Whose Space? Differences Among Users and Non-Users of Social Network Sites." Journal of Computer-Mediated Communication 13:276-97. 
2008. "The Digital Reproduction of Inequality." Pp. 936-44 in Social Stratification, edited by David Grusky. Boulder, CO: Westview Press.

2009. "An Update on Survey Measures of Web-Oriented Digital Literacy.” Social Science Computer Review 27(1):130-37.

Hargittai, Eszter and Amanda Hinnant. 2008. "Digital Inequality: Differences in Young Adults' Use of the Internet." Communication Research 35:602-21.

Hargittai, Eszter and Steven Shafer. 2006. "Differences in Actual and Perceived Online Skills: The Role of Gender." Social Science Quarterly 87:432-48.

Hargittai, Eszter and Gina Walejko. 2008. "The Participation Divide: Content Creation and Sharing in the Digital Age." Information, Communication \& Society 11:239-56.

Hassani, Sara Nephew. 2006. "Locating Digital Divides at Home, Work, and Everywhere Else." Poetics 34:250-72.

Hoffman, D. L. and T. P. Novak. 1998. "Bridging the Racial Divide on the Internet." Science (5362):390-91.

Howard, Philip N., Lee Rainie, and Steve Jones. 2001. "Days and Nights on the Internet: The Impact of a Diffusing Technology." American Behavioral Scientist 45:383-404.

Jones, S. and S. Fox. 2009. Generations Online in 2009. Washington, DC: Pew Internet \& American Life Project.

Kling, R.. 1998. "Technological and Social Access on Computing, Information and Communication Technologies." White Paper for Presidential Advisory Committee on HighPerformance Computing and Communications, Information Technology, and the Next Generation Internet.

Livingstone, Sonia and Ellen Helsper. 2007. "Gradations in Digital Inclusion: Children, Young People, and the Digital Divide." New Media and Society 9:671-96.

Loges, William E. and Joo-Young Jung. 2001. "Exploring the Digital Divide: Internet Connectedness and Age." Communications Research 28:536-62.

Michael J., Stern, Alison E. Adams and Shaun Elsasser. 2009. "Digital Inequality and Place: The Effects of Technological Diffusion on Internet Proficiency and Usage across Rural, Suburban, and Urban Counties." Sociological Inquiry 79(4):391-417.

National Opinion Research Center. 2000. General Social Survey Information Society Module. Chicago, IL: National Opinion Research Center.

National Telecommunications and Information Administration. 1995. Falling Through the Net: A Survey of the "Have Nots" in Rural and Urban America. Washington, DC: NTIA.

1998. Falling Through the Net II: New Data on the Digital Divide. Washington, DC: NTIA.

2000. Falling Through the Net: Toward Digital Inclusion. Washington, DC: NTIA.

Nielsen Wire. 2009. The More Affluent and More Urban are More Likely to Use Social Networks. Retrieved December 12, 2009. <http://blog.nielsen.com/nielsenwire/online_mobile/the-moreaffluent-and-more-urban-are-more-likely-to-use-social-networks/>

O'Brien, Catherine. 2008. How the Google Generation Thinks Differently. The Times. July 9, London.

Office of the President-Elect. 2008. President-Elect Barack Obama Lays Out Key Parts of the Economic Recovery Plan. Washington, DC: Office of the President-Elect.

Ono, Hiroshi and Madeline Zavodny. 2003. "Gender and the Internet." Social Science Quarterly 84:111-21.

Organization for Economic Cooperation and Development. 2008. Broadband Growth and Policies in OECD Countries. Paris: Organization for Economic Cooperation and Development.

Palfrey, John and Urs, Gasser. 2008. Born Digital: Understanding the First Generation of Digital Natives. New York: Basic Books. 
Prensky, M. 2001. "Digital Natives, Digital Immigrants." On the Horizon 9:1-6.

Selwyn, Neil. 2004. "Reconsidering Political and Popular Understandings of the Digital Divide." New Media \& Society 6:341-62.

Sewell, W. H. 1971. "Inequality of Opportunity for Higher Education." American Sociological Review 36:793-809.

Starr, Paul. 2004. The Creation of the Media: Political Origins of Modern Communications. New York: Basic Books.

Tapscott, D. 1998. Growing Up Digital: The Rise of the Net Generation. New York: McGraw Hill.

Warschauer, M. 2002. "Reconceptualizing the Digital Divide." First Monday 7(7): July.

Wasserman, Ira M. and Marie Richmond-Abbott. 2005. "Gender and the Internet: Causes of Variation in Access, Level, and Scope of Use." Social Science Quarterly 86:252-70.

Wilson, E. J. 2000. Closing the Digital Divide: An Initial Review: Briefing the President. Washington, DC: Internet Policy Institute.

Zhang, C., M. Callegaro, and M. Thomas. 2008. "More than the Digital Divide?: Investigating the Differences between Internet and Non-Internet Users." in Midwest Association of Public Opinion Research. Chicago, IL.

Zillien, Nicole and Eszter Hargittai. 2009. "Digital Distinction: Status-Specific Types of Internet Usage.” Social Science Quarterly 90:274-91. 